\title{
Genomics in Atrial Fibrillation: A Brief Review
}

\author{
Thomas E. Watts ${ }^{1}$, Abhishek J. Deshmukh ${ }^{2}$, Sadip Pant ${ }^{1}$, Juan Viles-Gonzalez ${ }^{3}$ and Hakan Paydak ${ }^{2}$ \\ ${ }^{1}$ Department of Internal Medicine, University of Arkansas for Medical Sciences, Little Rock, Arkansas, USA \\ ${ }^{2}$ Division of Cardiology, Department of Internal Medicine, University of Arkansas for Medical Sciences, Little Rock, Arkansas, USA \\ ${ }^{3}$ Division of Cardiology, Department of Internal Medicine, University of Miami, Miami, Florida, USA
}

*Corresponding author: Abhishek J Deshmukh, Division of Cardiology, Department of Internal Medicine, University of Arkansas for Medical Sciences, Little Rock, Arkansas, USA, Tel: 1-414-581-2153; Fax: 1-414-581-2153; E-mail: aJDeshmukh@uams.edu

Received date: 16 February 2014; Accepted date: 26 May 2014; Published date: 20 June 2014

Copyright: (c) 2014 Deshmukh AJ, et al. This is an open-access article distributed under the terms of the Creative Commons Attribution License, which permits unrestricted use, distribution, and reproduction in any medium, provided the original author(s) and source are credited.

\section{Genomics in Atrial Fibrillation}

Atrial fibrillation (AF) carries a significant burden in the form of morbidity, mortality, and cost to the healthcare system. According to the Center for Disease Control, AF is the most common cardiac arrhythmia in the United States with an incidence of 2.26 million people in 2010 that is expected to increase to 12 million people by 2050 [1]. The mortality rate from AF as a primary or secondary cause of death is increasing, as is the cost burden to the healthcare system [1]. It is estimated that in the year 2005, the cost to the U.S. healthcare system for treating AF was $\$ 6.65$ billion [1]. European population studies show a prevalence of AF of 5.5\%, with an incidence of 9.9 per 1000 person years [2]. The Rotterdam study showed that a 55-year-old European man had a $24.8 \%$ lifetime risk of developing AF [2]. In a 2010 Global Burden of Disease study the worldwide incidence of AF was estimated at 33.5 million people [3]. In this same study, the worldwide mortality rate from AF was found to have doubled from 1990 to 2010 [3]. Morbidity and mortality associated with AF arise from risk of thromboembolic stroke, tachycardia mediated cardiomyopathy, and from the treatment of the disease itself. Although the exact mechanism of AF is not known, what has been known for many years is that there is a probable genetic association for this disease. This is based on the fact that a strong family history of AF increases risk of one developing the disease [4]. Genetics in AF is an exciting area of research with implications that we could one day predict who will develop AF, choose therapy targeted to specific genotypes, and eventually prevent this disease in patients who are genetically predisposed to develop AF.

One of the initial genome wide association studies (GWAS) in AF was in an Icelandic population that found two variants on the 4q25 gene associated with AF. In this study, genome wide association was performed on 550 patients with AF and 4,476 controls in an Icelandic population. Of the 316,515 single-nucleotide polymorphisms (SNPs) that met the quality criteria, two located on chromosome $4 \mathrm{q} 25$ where found to have a significant association with AF when compared to healthy control subjects who did not carry these alleles. The two alleles on chromosome 4q25, rs2200733 and rs10033464, have a population allelic frequency of $12.05 \%$ and $8.53 \%$ respectively. This analysis was replicated in an additional group of Icelandic patients, as well as a population from Sweden, the United States, and Hong Kong [4].

Other genome wide association studies have identified SNPs at additional loci that are associated with AF. In the CHARGE-AF consortium 5,558 patients with $\mathrm{AF}$ and 41,178 controls, again demonstrated was the association with SNPs on the 4q25 locus; however, a new locus on the 16q22 gene was also found to have genome wide significant association with AF [5]. This was replicated by a study in an Icelandic population [6]. In a GWAS looking at 1335 patients with early-onset AF and 12,844 controls a SNP on chromosome 1q21 was found to have genome wide significant association with $\mathrm{AF}$ [7].

One group performed a GWAS looking at the heritability of the PR interval, as prolongation of the PR interval has been shown to carry increased risk of developing AF. There were nine loci that reached genome wide significant associations with PR interval, five of which were significant for an association with AF [8].

Showing association between SNPs on these three gene loci $4 \mathrm{q} 25$, $16 \mathrm{q} 22$, and 1q21 is promising; however, the mechanism of these associations or how we can therapeutically manipulate them is unclear. One area of promising research is in the PITX2 gene, which is located near the 4q25 gene [9]. PITX2c is the primary isoform of the PITX2 transcription factor that is expressed in the cardiac myocytes. PITX2c is thought to be involved in development of the left atrium, the conduction system, as well as the myocardial sheath surrounding the pulmonary veins [10]. Yang et al. published a study of a Chinese population looking for the prevalence of PITX2c mutations in familial AF. 152 patients with familial AF and 200 controls were enrolled for GWAS. Two mutations on the PITX2c gene were found in the group with familial AF. Interestingly, these mutations were not observed in the control group [10]. This was reproduced by two more recent studies that found heterozygous missense mutations on the PITX2c gene in a patient with familial AF as well as a patient lone AF that were not detected in healthy controls $[11,12]$. The association with the mutation of the PITX2c gene and AF could be explained by the role of the PITX2c gene in developing the myocardial sleeve of the pulmonary veins, which are a known and targeted source of initiation of AF. In an animal study, PITX2c knockout mice developed normal pulmonary veins that were lacking the myocardial sleeve [13]. Further associating this gene locus with underlying mechanisms of AF was a human study that showed significantly decreased PITX2c expression in patients with AF, suggesting that a loss of function of this gene predisposes to AF [14].

Despite the recent revelations in the genetics of $\mathrm{AF}$, these discoveries have not yet translated into changing clinical practice. There is still much to be learned about how genes play a role in the development of the disease and offer opportunity for intervention. It is possible that through current and future discoveries of genes related to $\mathrm{AF}$, and their transcription byproducts that we will one day come to understand the exact pathophysiologic mechanism of the disease. The genetic associations of AF offer the opportunity for future therapies such as gene-targeted therapy, pharmacogenetic therapy, as well as early detection, and hopefully one day prevention of this problematic disease. 
Citation: Watts TE, Deshmukh AJ, Pant S, Gonzalez JV and Paydak H (2014) Genomics in Atrial Fibrillation: A Brief Review. J Mol Genet Med

Page 2 of 2

\section{References}

1. CDC, Atrial Fibrillation Fact Sheet. 2014. Infographic. CDC.com.

2. Heeringa J, van der Kuip DA, Hofman A, Kors JA, van Herpen G, et al (2006) Prevalence, incidence and lifetime risk of atrial fibrillation: the Rotterdam study. Eur Heart J 27: 949-953.

3. Chugh SS, Havmoeller R, Narayanan K, Singh D, Rienstra M, et al. (2014) Worldwide epidemiology of atrial fibrillation: a Global Burden of Disease 2010 Study. Circulation 129: 837-847.

4. Gudbjartsson DF, Arnar DO, Helgadottir A, Gretarsdottir S, Holm H, et al. (2007) Variants conferring risk of atrial fibrillation on chromosome 4q25. Nature 448: 353-357.

5. Psaty BM, O'Donnell CJ, Gudnason V, Lunetta KL, Folsom AR, et al (2009) Cohorts for Heart and Aging Research in Genomic Epidemiology (CHARGE) Consortium: Design of prospective meta-analyses of genome-wide association studies from 5 cohorts. Circ Cardiovasc Genet 2: 73-80.

6. Gudbjartsson DF, Holm H, Gretarsdottir S, Thorleifsson G, Walters GB, et al. (2009) A sequence variant in ZFHX3 on 16q22 associates with atrial fibrillation and ischemic stroke. Nat Genet 41: 76-878.

7. Ellinor PT, Lunetta KL, Glazer NL, Pfeufer A, Alonso A, et al. (2010) Common variants in KCNN3 are associated with lone atrial fibrillation. Nat Genet 42: 240-244.
8. Pfeufer A, van Noord C, Marciante KD, Arking DE, Larson MG, et al. (2010) Genome-wide association study of PR interval. Nat Genet 42: 153-159.

9. Sinner MF, Ellinor PT, Meitinger T, Benjamin EJ, Kääb S (2011) Genome-wide association studies of atrial fibrillation: past, present, and future. Cardiovasc Res 89: 701-709.

10. Yang YQ, Xu YJ, Li RG, Qu XK, Fang WY, et al. (2013) Prevalence and spectrum of PITX2c mutations associated with familial atrial fibrillation. Int J Cardiol 168: 2873-2876.

11. Wang J, Zhang DF2, Sun YM3, Yang YQ4 (2014) A novel PITX2c lossof-function mutation associated with familial atrial fibrillation. Eur J Med Genet 57: 25-31.

12. Zhou, Yi Meng, Peng Xiang Zheng, et al. (2013) "A novel PITX2c loss of function mutation underlies lone atrial fibrillation." International Journal of Molecular Medicine. 32.4: 827-834.

13. Mommersteeg MT, Brown NA, Prall OW, de Gier-de Vries C, Harvey $\mathrm{RP}$, et al. (2007) Pitx2c and Nkx2-5 are required for the formation and identity of the pulmonary myocardium. Circ Res 101: 902-909.

14. Chinchilla A, Daimi H, Lozano-Velasco E, Dominguez JN, Caballero R, et al. (2011) PITX2 insufficiency leads to atrial electrical and structural remodeling linked to arrhythmogenesis. Circ Cardiovasc Genet 4: 269-279. 